\title{
Determining early referral criteria for patients with suspected inflammatory arthritis presenting to primary care physicians: a cross-sectional study
}

This article was published in the following Dove Press journal:

Open Access Rheumatology: Research and Reviews

27 April 2017

Number of times this article has been viewed

\author{
Hani Almoallim ${ }^{1-3}$ \\ Nahid Janoudi ${ }^{2}$ \\ Suzan M Attar ${ }^{4}$ \\ Mohammed Garout ${ }^{5}$ \\ Shereen Algohary ${ }^{3}$ \\ Muhammad Irfanullah \\ Siddiqui ${ }^{5}$ \\ Hanan Alosaimi ${ }^{3}$ \\ Ashraf Ibrahim ${ }^{3}$ \\ Amira Badokhon ${ }^{6}$ \\ Zaki Algasemi ${ }^{7}$ \\ 'Department of Medicine, Medical \\ College, Umm Alqura University, \\ Makkah, ${ }^{2}$ Department of Medicine, \\ Dr. Soliman Fakeeh Hospital, \\ Jeddah, ${ }^{3}$ Alzaidi Chair of Research \\ in Rheumatic Diseases, Medical \\ College, Umm Alqura University, \\ Makkah, ${ }^{4}$ Department of Medicine, \\ King Abdulaziz University, Jeddah, \\ ${ }^{5}$ Department of Community Medicine \\ and Public Health, Umm Alqura \\ University, Makkah, ${ }^{6}$ Administration \\ of Public Health, Ministry of Health, \\ Jeddah, ${ }^{7}$ Joint Program of Family and \\ Community Medicine, Ministry of \\ Health, Jeddah, Kingdom of Saudi \\ Arabia
}

Correspondence: Hani Almoallim Department of Medicine, Medical College, Umm Alqura University, PO Box I82I, Jeddah 21441, Kingdom of Saudi Arabia

Tel +966 I2 505703935

Fax +966I2 5270000 ext 7III0

Email hmmoallim@uqu.edu.sa
Objective: Early diagnosis and initiation of treatment for inflammatory arthritis can greatly improve patient outcome. We aimed to provide standardized and validated criteria for use by primary care physicians (PCPs) in the identification of individuals requiring referral to a rheumatologist.

Patients and methods: We analyzed the predictive value of a wide variety of demographic variables, patient-reported complaints, physical examination results, and biomarkers in order to identify the most useful factors for indicating a requirement for referral. Patients for this cross-sectional study were enrolled from various centers of the city of Jeddah, Saudi Arabia, if they were $\geq 18$ years of age and presented to a PCP with small joint pain that had been present for more than 6 weeks. A total of 203 patients were enrolled, as indicated by the sample size calculation. Each patient underwent a standardized physical examination, which was subsequently compared to ultrasound findings. Biomarker analysis and a patient interview were also carried out. Results were then correlated with the final diagnosis made by a rheumatologist.

Results: A total of 9 variables were identified as having high specificity and good predictive value: loss of appetite, swelling of metacarpophalangeal joint 2 or 5, swelling of proximal interphalangeal joint 2 or 3, wrist swelling, wrist tenderness, a positive test for rheumatoid factor, and a positive test for anti-citrullinated protein antibodies.

Conclusion: Nine variables should be the basis of early referral criteria. It should aid PCPs in making appropriate early referrals of patients with suspected inflammatory arthritis, accelerating diagnosis and initiation of treatment.

Keywords: inflammatory arthritis, rheumatoid, diagnosis, primary care, early referral criteria

\section{Introduction}

Early diagnosis of inflammatory arthritis is essential for achieving the best possible outcome for patients. ${ }^{1,2}$ It is known that initiation of pharmacological treatment at the earliest opportunity can significantly reduce disease progression..$^{3-5}$

A primary care physician (PCP) is usually the first point of contact for a patient experiencing joint pain; however, it is generally a rheumatologist who provides the final diagnosis. ${ }^{6,7}$ Therefore, there is a need to optimize the process of transition from the primary care center to the specialist in order to achieve a timely diagnosis. ${ }^{7,8}$ Whilst previous studies have outlined potential criteria that could aid a PCP in identifying patients who require early referral to a rheumatology service, these have been based 
on literature searches and discussions among specialists. ${ }^{2,9}$ There are currently no criteria that have been identified and validated using a population of arthritis patients.

A further shortcoming of previously established criteria is the lack of standardization of examination techniques. While ultrasound and magnetic resonance imaging is increasingly used to diagnose inflammatory arthritis, these are often not available in the primary care setting. ${ }^{10}$ Therefore, the ability of a PCP to carry out an accurate musculoskeletal examination is essential for achieving a prompt referral to a rheumatologist. It has been shown that skills in this area are lacking in physicians, with improvements in training being necessary. ${ }^{11-13}$ The introduction of standardized techniques would help in overcoming these issues.

In response to this need, a recent study defined and validated an approach to perform an effective musculoskeletal examination of the hand and wrist joints for diagnosis of inflammatory arthritis. ${ }^{14}$ They reported that these standardized techniques could achieve sensitivities in the range of approximately $70-80 \%$ for detection of arthritis, with ultrasound used for validation. Building on these results, we here aimed to produce a set of guidelines using these standardized techniques, in addition to blood analysis, which could be the basis of criteria used by PCPs to aid the identification of patients requiring early referral to a rheumatologist.

\section{Patients and methods Study design}

This study was conducted to find out sensitivity and specificity of variables that can be included in early referral criteria for the diagnosis of arthritis, with a hypothesis that training of PCPs regarding the criteria for early diagnosis of arthritis will increase the early referral of patients to rheumatologist; hence, estimation of sample size was essential to apply tools of statistics, given the sensitivity (80\%), specificity (70\%), and prevalence of the disease as $60 \%$. We consulted a professional biostatistician, who helped us in sample size calculation and data analysis. We considered the value of design effects as 2 to calculate sample size, based on design effects and intraclass correlations.

Potential comprehensive referral criteria were decided upon by a committee consisting of 3 rheumatologists, an expert epidemiologist, and researchers after a thorough search of the literature. The help of biostatistician was sought to calculate sample size and analysis of result to accommodate loss of variability due to sampling technique. These criteria were then used by the PCP when considering a rheumatology referral (Patient Referral Form A) (Figure
1). On attendance at the rheumatology clinic, each patient underwent musculoskeletal examination by a rheumatologist (Patient Referral Form B) and ultrasonography by a trained sonographer (Patient Referral Form C), with each examiner blinded to the findings of the other and to those of the PCP. Patients also underwent blood testing at both a regional laboratory and Fakeeh Hospital. A final diagnosis was made by the rheumatologist after reviewing the findings documented on the referral forms and those of the blood work. The association of each variable in the comprehensive referral criteria with an arthritis diagnosis was then determined using statistical analysis. A final set of variables highly correlated with the final diagnosis of arthritis was then established. These should be the basis of validated referral criteria. The question of how to use these variables by a PCP is not addressed in this paper.

\section{Setting and patients}

This cross-sectional study was conducted at primary health care centers (PHC) under the auspices of the Administration of Public Health within the Ministry of Health in Jeddah (Saudi Arabia).

Jeddah is second largest city of KSA and the largest sea port at Red Sea with a population of about 3.4 million. There are total of 39 PHC centers in four regions of Jeddah. At first stage, four PHC centers were selected by adopting simple random sampling technique among the total 39 PHC centers, one from each region, followed by selection of all those patients who met eligibility criteria. There were 3 rheumatologists and 40 PCPs enrolled in the study to find out the sensitivity and specificity of early referral criteria. There was only one ultrasonography (US), who did ultrosonology on all patients. US data were not used for the referral variables but helped in reaching final diagnosis and were part of four categories of variables used to conclude about the state of arthritis, which were as follows:

1. data from ultrasound examination,

2. findings of rheumatologist,

3. laboratory findings

4. findings of PCP.

Patients were enrolled if they were $\geq 18$ years of age and presented to a PCP with small joint pain that had been present for more than 6 weeks. Patients were excluded if they had an established rheumatological diagnosis or had osteoarthritis of the hands, which was either previously diagnosed or presented as bony swellings over the distal inter-phalangeal or 


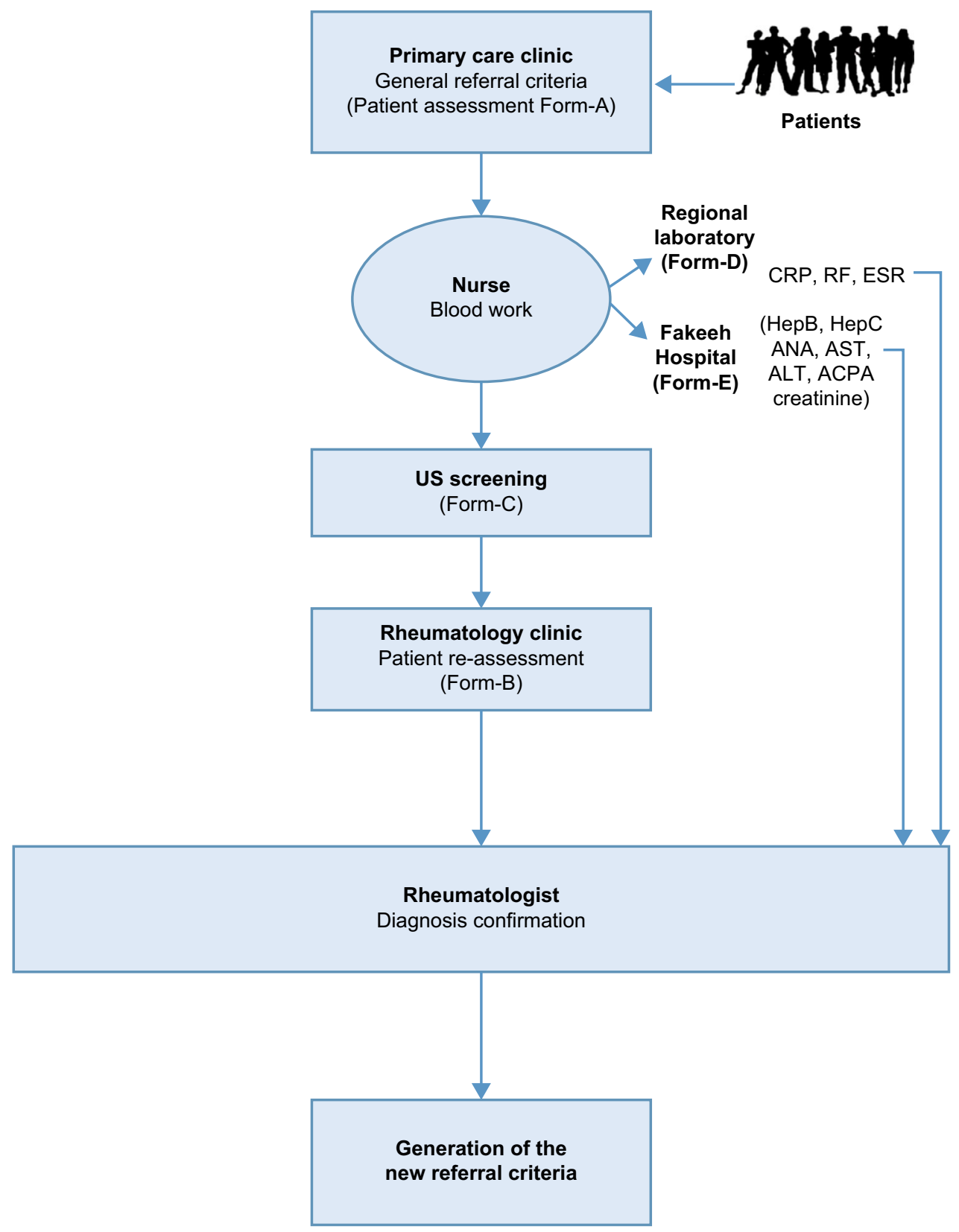

Figure I Study design.

Abbreviations: CPR, C-reactive protein; RF, rheumatoid factor; ESR, erythrocyte sedimentation rate; Hep, hepatitis; ANA, antinuclear antibody; AST, aspartate aminotransferase; ALT, alanine aminotransferase; ACPA, anti-citrullinated protein antibodies; US, ultrasonography.

proximal inter-phalangeal (PIP) joints. A history of hand and/ or wrist fracture was a further exclusion criterion.

All included patients provided written informed consent, and the study received ethical approval from the institutional review boards of each participating center (Dr. Soliman Fakeeh Hospital and King Abdulaziz University Hospital), as well as the Research Administration of the Directorate of Health Affairs at the Ministry of Health. Furthermore, the study was conducted in accordance with the Declaration of Helsinki and its amendments. Consent for publishing this study was obtained from all the authors.

\section{Examinations performed by PCPs}

A standard approach for musculoskeletal examination was used by both the PCP and the rheumatologist (Figure 2). Twodays of training were conducted for every PCP, this was completed 1 week prior to initiation of the study. It was made sure by the rheumatologists, before concluding the training session, that PCPs were applying correct technique to detect musculoskeletal disorders. Ultrasonography was performed on the PIP, metacarpophalangeal (MCP), and wrist joints. Blood analysis performed at the regional laboratory consisted of assessment of levels of C-reactive protein (CRP) and rheumatoid factor 
Metacarpophalangeal joint assessment - scissor technique

- A scissor-like shape is made with the fingers (a).

- The patient's hand is held from the sides at the MCP level (b).

- The MCPs are flexed to 90 degrees (b).

- The thumbs are used to palpate the joint - one to apply pressure to the joint, the other to assess for effusion, swelling, and/or tenderness (b).

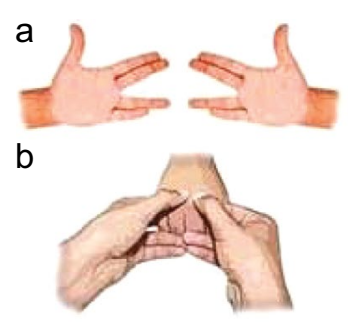

Proximal inter-phalangeal joint assessment - four-finger technique

- Each PIP is held by the thumb and index finger of one hand of the examiner.

- Pressure is applied until the distal finger becomes whitened due to low blood supply.

- The thumb and index finger of the examiner's other hand are used palpate the joint to identify effusion, swelling, and/or tenderness.

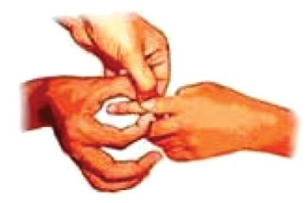

Wrist palpitation - two-thumb technique

- The examiner's thumb should follow the 3rd metacarpal bone on the dorsal aspect of the hand until a dimple is reached at the capitate level.

- Continuous pressure is exerted by the thumb.

- The other thumb is used to intermittently apply pressure approximately half an inch away on the wrist joint in order to identify swelling and/or tenderness.

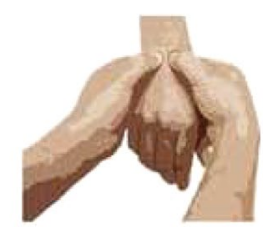

Figure 2 Standardized musculoskeletal examination procedures.

Note: The described techniques for physical examination should be performed by a trained clinician.

Abbreviations: MCP, metacarpophalangeal; PIP, proximal inter-phalangeal.

(RF), in addition to determination of erythrocyte sedimentation rate. Further tests at Fakeeh Hospital investigated hepatitis $\mathrm{B}$ and $\mathrm{C}$, and levels of antinuclear antibody (ANA), aspartate aminotransferase, alanine aminotransferase, creatinine, and anti-citrullinated protein antibodies (ACPA).

A systematic multi-planar grayscale and power Doppler US examination of the PIP, MCP, and two wrist joints were performed. Ultrasonography was performed using LPGIQ 9 scanner (GE Healthcare, Milwaukee, WI, USA) with a high frequency linear array $12-\mathrm{MHz}$ transducer. A standardized acquisition protocol was used in the scanning techniques and definition of pathology. Both dorsal and volar aspects of the joints were scanned. The scanning was done in three positions for each hand. The scanning was done in two positions of each hand and wrist joints. The first position was the wrist MCP and PIP joints in a posterior (dorsal) longitudinal position in relation to the probe of the US. The second position was with the wrist, MCP and PIP joints in an anterior (volar) longitudinal position in relation to the probe of the US. This test helped to reach the final diagnosis in addition to the rheumatologist findings and laboratory results.

\section{Statistical analysis}

As the objectives of the study were to find a screening tool for inflammatory arthritis that can be included in early referral criteria, the sample size was calculated based on an expected sensitivity of $80 \%$, specificity of $70 \%$, and prevalence of $60 \%$, with a precision of $10 \%$ and a confidence interval of $95 \% .{ }^{15}$ An adequate sample was essential to have reasonable power of study to determine the association. To minimize the decrease variability due to sampling technique, we increased the design effect (DEFF) (which helps in direct estimation of confidence interval) to 2 . This provided a sample size of 203 patients who were referred to the rheumatologist. The association between variables and a positive diagnosis of inflammatory arthritis was evaluated using chi-square test, or Fisher's exact test for the assessment of swelling of the right PIP 5, which did not fulfil chi-square criteria. These analyses were carried out using SPSS v.20 (IBM Corporation, Armonk, NY, USA). Variables that showed a significant association with diagnosis were subjected to further evaluation using the Epi 3 software (Centre of Disease Control, Atlanta, GA, USA ) for analysis of data to determine sensitivity, specificity, positive predictive value (PPV), negative predictive value, diagnostic accuracy, and likelihood ratios. The Wilson score was used to give $95 \%$ confidence intervals. Finally, the variables that should form the basis of referral criteria were finalized using logistic regression.

\section{Results}

Of the 203 patients enrolled in the study, data from 1 were excluded owing to incomplete information. Of the remaining 
202 patients, $63.4 \%$ were aged 40 years or older, and $81.7 \%$ were females. No associations were found between age and sex with a positive inflammatory arthritis diagnosis (Table 1). However, in terms of patient-reported complaints, loss of appetite $(p=0.04)$, stiffness ( $p=0.02)$, and a family history of uveitis ( $p=0.01)$ were significantly associated (Table 1$)$. A number of the musculoskeletal examination parameters were also found to be linked to diagnosis (Table 2), as were CRP, RF, and ACPA (Table 3).

Subsequent analysis of the variables that showed an association with a positive diagnosis indicated that 13 had a specificity greater than $90 \%$ in combination with a good PPV and likelihood ratio (Table 4). We selected a set of variables to form the basis of referral criteria. These variables were defines by applying logistic regression: loss of appetite, swelling of MCP 2 or MCP 5, swelling of PIP 2 or PIP 3, wrist swelling, wrist tenderness, RF positivity, and ACPA positivity (Table 5). We calculated percent agreement for the 6 identified referral criteria, examined by both rheumatologist and PHP, which included; MCP 2, MCP 5, PIP 2, PIP 3, wrist swelling, and wrist tenderness by applying kappa statistics and found the values as $0.229(p$-value $=0.001), 0.261(p$-value $=0.000)$, $0.38(p$-value $=0.000), 0.187(p$-value $=0.008), 0.425(p$-value $=0.000)$, and $0.479(p$-value $=0.000)$, respectively.

\section{Discussion}

The progressive nature of inflammatory arthritis means that a delay in diagnosis and initiation of treatment can result in a significantly poorer outcome for patients. ${ }^{2,4,5,7}$ The time

Table I Demographic and patient-reported variables with their association to positive diagnosis of inflammatory arthritis

\begin{tabular}{|c|c|c|c|c|}
\hline & \multirow[t]{2}{*}{$\mathbf{N}$} & \multicolumn{2}{|c|}{ Disease status } & \multirow[t]{2}{*}{ p-value* } \\
\hline & & Yes & No & \\
\hline \multicolumn{5}{|l|}{ Demographics } \\
\hline \multicolumn{5}{|l|}{ Sex } \\
\hline Male & 37 & 24 & 13 & 0.496 \\
\hline Female & 165 & 104 & 61 & \\
\hline \multicolumn{5}{|l|}{ Age } \\
\hline$<40$ years & 74 & 52 & 22 & $0.08 I$ \\
\hline$\geq 40$ years & 128 & 76 & 52 & \\
\hline \multicolumn{5}{|l|}{ Patient-reported } \\
\hline \multicolumn{5}{|c|}{ Loss of appetite } \\
\hline Yes & 31 & 25 & 6 & 0.04 \\
\hline No & 171 & 103 & 68 & \\
\hline \multicolumn{5}{|l|}{ Stiffness } \\
\hline Yes & 93 & 51 & 42 & 0.02 \\
\hline No & 109 & 77 & 32 & \\
\hline \multicolumn{5}{|c|}{ Family history of uveitis } \\
\hline Yes & 7 & 1 & 6 & 0.01 \\
\hline No & 195 & 127 & 68 & \\
\hline
\end{tabular}

Note: ${ }^{*}$ Chi-square test.
Table 2 Musculoskeletal parameters significantly associated with a positive diagnosis of inflammatory arthritis

\begin{tabular}{|c|c|c|c|c|}
\hline & \multirow[t]{2}{*}{$\mathbf{N}$} & \multicolumn{2}{|c|}{ Disease status } & \multirow[t]{2}{*}{$p$-value } \\
\hline & & Yes & No & \\
\hline \multicolumn{5}{|c|}{ Metacarpophalangeal joints } \\
\hline \multicolumn{5}{|c|}{ Swelling of MCP 2 (right) } \\
\hline Yes & 26 & 21 & 5 & 0.048 \\
\hline No & 176 & 107 & 69 & \\
\hline \multicolumn{5}{|c|}{ Swelling of MCP 2 (left) } \\
\hline Yes & 27 & 23 & 4 & 0.008 \\
\hline No & 175 & 105 & 70 & \\
\hline \multicolumn{5}{|c|}{ Swelling of MCP 5 (right) } \\
\hline Yes & 7 & 7 & 0 & 0.036 \\
\hline No & 195 & 121 & 74 & \\
\hline \multicolumn{5}{|c|}{ Swelling of MCP 3 (left) } \\
\hline Yes & 26 & 21 & 5 & 0.036 \\
\hline No & 176 & 107 & 69 & \\
\hline \multicolumn{5}{|c|}{ Tenderness of MCP I (right) } \\
\hline Yes & 57 & 42 & 15 & 0.038 \\
\hline No & 145 & 86 & 59 & \\
\hline \multicolumn{5}{|c|}{ Tenderness of MCP I (left) } \\
\hline Yes & 61 & 47 & 14 & 0.006 \\
\hline No & $|4|$ & 81 & 60 & \\
\hline \multicolumn{5}{|c|}{ Tenderness of MCP 2 (left) } \\
\hline Yes & 73 & 53 & 20 & 0.028 \\
\hline No & 129 & 75 & 54 & \\
\hline \multicolumn{5}{|c|}{ Proximal inter-phalangeal joints } \\
\hline \multicolumn{5}{|c|}{ Swelling of PIP 2 (right) } \\
\hline Yes & 29 & 25 & 4 & 0.006 \\
\hline No & 173 & 103 & 70 & \\
\hline \multicolumn{5}{|c|}{ Swelling of PIP 2 (left) } \\
\hline Yes & 29 & 25 & 4 & 0.006 \\
\hline No & 173 & 103 & 70 & \\
\hline \multicolumn{5}{|c|}{ Swelling of PIP 3 (right) } \\
\hline Yes & 34 & 28 & 6 & 0.011 \\
\hline No & 168 & 100 & 68 & \\
\hline \multicolumn{5}{|c|}{ Swelling of PIP 3 (left) } \\
\hline Yes & 32 & 26 & 6 & 0.027 \\
\hline No & 170 & 102 & 68 & \\
\hline \multicolumn{5}{|c|}{ Swelling of PIP 5 (right) } \\
\hline Yes & 12 & 11 & I & $0.036 *$ \\
\hline No & 190 & 117 & 73 & \\
\hline \multicolumn{5}{|c|}{ Wrist } \\
\hline \multicolumn{5}{|c|}{ Swelling of the wrist (right) } \\
\hline Yes & 42 & 37 & 5 & 0.001 \\
\hline No & 160 & 91 & 69 & \\
\hline \multicolumn{5}{|c|}{ Tenderness of the wrist (right) } \\
\hline Yes & 42 & 36 & 6 & 0.001 \\
\hline No & 160 & 92 & 68 & \\
\hline
\end{tabular}

Note: $p$-values calculated using the chi-square test, except *Fisher's exact test. Abbreviations: MCP, metacarpophalangeal; PIP, proximal inter-phalangeal.

between symptom onset and diagnosis of rheumatoid arthritis by a rheumatologist in Saudi Arabia has been reported to be as high as 30 months. ${ }^{16}$ In comparison, a French study calculated an average of 53 days between PCP visit and rheumatologist assessment. ${ }^{17}$ In a multicenter European study, a rheumatologist found that the lag time between symptom 
onset and assessment was approximately 24 weeks, and the time from PCP to specialist was between 2 and 10 weeks. ${ }^{18}$

In this study, we determined several MSK examination findings based on specified and validated techniques to be significantly associated with the early detection and referrals

Table 3 Blood parameters significantly associated with a positive diagnosis of inflammatory arthritis

\begin{tabular}{|c|c|c|c|c|}
\hline & \multirow[t]{2}{*}{$\mathbf{N}$} & \multicolumn{2}{|c|}{ Disease status } & \multirow[t]{2}{*}{$p$-value } \\
\hline & & Yes & No & \\
\hline \multicolumn{5}{|l|}{ CRP } \\
\hline Positive & 26 & 21 & 5 & 0.048 \\
\hline Negative & 176 & 107 & 69 & \\
\hline \multicolumn{5}{|l|}{ RF } \\
\hline Positive & 28 & 24 & 4 & 0.008 \\
\hline Negative & 166 & 99 & 67 & \\
\hline \multicolumn{5}{|l|}{ ACPA } \\
\hline Positive & 30 & 28 & 2 & 0.001 \\
\hline Negative & 160 & 91 & 69 & \\
\hline
\end{tabular}

Abbreviations: CRP, C-reactive protein; RF, rheumatoid factor; ACPA, anticitrullinated protein antibodies. of arthritis by the PCP. This was in particular for techniques that were able to detect swellings not tenderness in the second MCP, fifth MCP, second PIP, third PIP, fifth PIP, and wrist joints. As expected, RF and ACPA positivity in early disease in our cohort of patients were significantly correlated with early detection. We found symptoms associated with arthritis like fatigue and morning stiffness to be not specific and showed poor PPV for early detection of arthritis by a PCP. This is a step towards creating validated early referral criteria for inflammatory arthritis.

Previous attempts to produce a set of guidelines to be used in the primary care setting have been based on literature surveys and discussions among professionals. ${ }^{2,9}$ Emery et al specified 3 criteria, each of which indicated that a referral was appropriate for suspected rheumatoid arthritis: $\geq 3$ swollen joints; a positive squeeze test, indicating MCP involvement; and morning stiffness of $\geq 30$ minutes. ${ }^{2}$ Suresh et al additionally specified fatigue or weight loss, raised inflammatory markers, and a positive test for RF as indicators for referral. ${ }^{9}$ However, there appears to be a distinct lack of studies evalu-

Table 4 Analysis of variables showing an association with a positive diagnosis of inflammatory arthritis

\begin{tabular}{|c|c|c|c|c|c|c|c|}
\hline & Sensitivity & Specificity & PPV & NPV & $\begin{array}{l}\text { Diagnostic } \\
\text { accuracy }\end{array}$ & $\begin{array}{l}\text { Likelihood } \\
\text { ratio } \\
\text { (positive) }\end{array}$ & $\begin{array}{l}\text { Likelihood } \\
\text { ratio } \\
\text { (negative) }\end{array}$ \\
\hline Loss of appetite & $\begin{array}{l}19.5 \% \\
(13.6-27.2)\end{array}$ & $\begin{array}{l}89.47 \% \\
(80.6-94.6)\end{array}$ & $\begin{array}{l}75.8 \% \\
(59.0-87.2)\end{array}$ & $\begin{array}{l}39.8 \% \\
(32.7-47.3)\end{array}$ & $\begin{array}{l}45.6 \% \\
(39.0-52.4)\end{array}$ & $\begin{array}{l}1.9 \\
(1.1-3.3)\end{array}$ & $\begin{array}{l}0.90 \\
(0.88-0.92)\end{array}$ \\
\hline Swelling of MCP 2 (right) & $\begin{array}{l}16.4 \% \\
(11.0-23.8)\end{array}$ & $\begin{array}{l}93.2 \% \\
(85.1-97.1)\end{array}$ & $\begin{array}{l}80.8 \% \\
(62.1-91.5)\end{array}$ & $\begin{array}{l}39.2 \% \\
(32.3-46.6)\end{array}$ & $\begin{array}{l}44.6 \% \\
(37.9-51.5)\end{array}$ & $\begin{array}{l}2.5 \\
(1.0-5.8)\end{array}$ & $\begin{array}{l}0.9 \\
(0.9-0.9)\end{array}$ \\
\hline Swelling of MCP 2 (left) & $\begin{array}{l}18.0 \% \\
(12.3-25.5)\end{array}$ & $\begin{array}{l}94.6 \% \\
(86.9-97.9)\end{array}$ & $\begin{array}{l}85.2 \% \\
(67.5-94.1)\end{array}$ & $\begin{array}{l}40.0 \% \\
(33.0-47.4)\end{array}$ & $\begin{array}{l}46.0 \% \\
(39.3-52.9)\end{array}$ & $\begin{array}{l}3.3 \\
(1.4-8.0)\end{array}$ & $\begin{array}{l}0.9 \\
(0.8-0.9)\end{array}$ \\
\hline Swelling of MCP 5 (right) & $\begin{array}{l}5.5 \% \\
(2.7-10.9)\end{array}$ & $\begin{array}{l}100.0 \% \\
(95.1-100.0)\end{array}$ & $\begin{array}{l}100.0 \% \\
(64.6-100.0)\end{array}$ & $\begin{array}{l}38.0 \% \\
(31.4-44.9)\end{array}$ & $\begin{array}{l}40.1 \% \\
(33.6-47.0)\end{array}$ & undefined & $\begin{array}{l}1.0 \\
(0.9-1.0)\end{array}$ \\
\hline Swelling of PIP 2 (right) & $\begin{array}{l}19.5 \% \\
(13.6-27.2)\end{array}$ & $\begin{array}{l}94.6 \% \\
(86.9-97.9)\end{array}$ & $\begin{array}{l}86.2 \% \\
(69.4-94.5)\end{array}$ & $\begin{array}{l}40.5 \% \\
(33.4-47.9)\end{array}$ & $\begin{array}{l}47.0 \% \\
(40.3-53.9)\end{array}$ & $\begin{array}{l}3.6 \\
(1.6-8.1)\end{array}$ & $\begin{array}{l}0.9 \\
(0.8-0.9)\end{array}$ \\
\hline Swelling of PIP 2 (left) & $\begin{array}{l}18.0 \% \\
(12.3-25.5)\end{array}$ & $\begin{array}{l}91.9 \% \\
(83.4-96.2)\end{array}$ & $\begin{array}{l}79.3 \% \\
(61.6-90.2)\end{array}$ & $\begin{array}{l}39.3 \% \\
(32.3-46.7)\end{array}$ & $\begin{array}{l}45.1 \% \\
(38.3-51.9)\end{array}$ & $\begin{array}{l}2.2 \\
(I .1-4.5)\end{array}$ & $\begin{array}{l}0.9 \\
(0.9-0.9)\end{array}$ \\
\hline Swelling of PIP 3 (right) & $\begin{array}{l}21.9 \% \\
(15.6-29.8)\end{array}$ & $\begin{array}{l}91.9 \% \\
(83.4-96.2)\end{array}$ & $\begin{array}{l}82.4 \% \\
(66.5-91.7)\end{array}$ & $\begin{array}{l}40.5 \% \\
(33.4-48.0)\end{array}$ & $\begin{array}{l}47.5 \% \\
(40.8-54.4)\end{array}$ & $\begin{array}{l}2.7 \\
(1.5-4.8)\end{array}$ & $\begin{array}{l}0.9 \\
(0.8-0.9)\end{array}$ \\
\hline Swelling of PIP 3 (left) & $\begin{array}{l}20.3 \% \\
(14.3-28.1)\end{array}$ & $\begin{array}{l}91.9 \% \\
(83.4-96.2)\end{array}$ & $\begin{array}{l}81.3 \% \\
(64.7-91.1)\end{array}$ & $\begin{array}{l}40.0 \% \\
(32.9-47.5)\end{array}$ & $\begin{array}{l}46.5 \% \\
(39.8-53.4)\end{array}$ & $\begin{array}{l}2.5 \\
(1.3-4.7)\end{array}$ & $\begin{array}{l}0.9 \\
(0.8-0.9)\end{array}$ \\
\hline Swelling of PIP 5 (right) & $\begin{array}{l}8.6 \% \\
(4.9-14.7)\end{array}$ & $\begin{array}{l}98.7 \% \\
(92.7-99.8)\end{array}$ & $\begin{array}{l}91.7 \% \\
(64.6-98.5)\end{array}$ & $\begin{array}{l}38.4 \% \\
(31.8-45.5)\end{array}$ & $\begin{array}{l}41.6 \% \\
(35.0-48.5)\end{array}$ & $\begin{array}{l}6.4 \\
(0.1-300.4)\end{array}$ & $\begin{array}{l}0.9 \\
(0.9-0.9)\end{array}$ \\
\hline Swelling of wrist (right) & $\begin{array}{l}28.9 \% \\
(21.8-37.3)\end{array}$ & $\begin{array}{l}93.2 \% \\
(85.1-97.1)\end{array}$ & $\begin{array}{l}88.1 \% \\
(75.0-94.8)\end{array}$ & $\begin{array}{l}43.1 \% \\
(35.7-50.9)\end{array}$ & $\begin{array}{l}52.5 \% \\
(45.6-59.3)\end{array}$ & $\begin{array}{l}4.3 \\
(2.5-7.2)\end{array}$ & $\begin{array}{l}0.8 \\
(0.7-0.8)\end{array}$ \\
\hline $\begin{array}{l}\text { Tenderness of wrist } \\
\text { (right) }\end{array}$ & $\begin{array}{l}28.1 \% \\
(21.1-36.5)\end{array}$ & $\begin{array}{l}91.9 \% \\
(83.4-96.2)\end{array}$ & $\begin{array}{l}85.7 \% \\
(72.2-93.3)\end{array}$ & $\begin{array}{l}42.5 \% \\
(35.1-50.3)\end{array}$ & $\begin{array}{l}51.5 \% \\
(44.6-58.3)\end{array}$ & $\begin{array}{l}3.5 \\
(2.2-5.5)\end{array}$ & $\begin{array}{l}0.8 \\
(0.8-0.8)\end{array}$ \\
\hline RF positive & $\begin{array}{l}19.5 \% \\
(13.5-27.4)\end{array}$ & $\begin{array}{l}94.4 \% \\
(86.4-97.8)\end{array}$ & $\begin{array}{l}85.7 \% \\
(68.5-94.3)\end{array}$ & $\begin{array}{l}40.4 \% \\
(33.2-48.0)\end{array}$ & $\begin{array}{l}46.9 \% \\
(40.0-53.9)\end{array}$ & $\begin{array}{l}3.5 \\
(1.5-7.9)\end{array}$ & $\begin{array}{l}0.9 \\
(0.8-0.9)\end{array}$ \\
\hline ACPA positive & $\begin{array}{l}23.5 \% \\
(16.8-31.9)\end{array}$ & $\begin{array}{l}97.2 \% \\
(90.3-99.2)\end{array}$ & $\begin{array}{l}93.3 \% \\
(78.7-98.2)\end{array}$ & $\begin{array}{l}43.1 \% \\
(35.7-50.9)\end{array}$ & $\begin{array}{l}51.1 \% \\
(44.0-58.1)\end{array}$ & $\begin{array}{l}8.5 \\
(2.5-27.9)\end{array}$ & $\begin{array}{l}0.8 \\
(0.8-0.8)\end{array}$ \\
\hline
\end{tabular}

Note: $95 \%$ confidence intervals correspond to Wilson's score intervals.

Abbreviations: PPV, positive predictive value; NPV, negative predictive value; MCP, metacarpophalangeal; PIP, proximal inter-phalangeal; RF, rheumatoid factor; ACPA, anti-citrullinated protein antibodies. 
Table 5 Suggested variables that should be included in a referral criteria (based on variables that showed $>90 \%$ specificity and good positive predictive value and likelihood ratio)

\begin{tabular}{lll}
\hline No. & Criteria & How to assess \\
\hline $\mathrm{l}$ & Loss of appetite & History taking \\
2 & MCP 2 swelling either in & MCP scissor technique: \\
& right and/or left hand & The examiner should make a scissor-like shape with his/her fingers, joining the index and middle
\end{tabular}
right and/or left hand fingers together while joining the ring and little finger together, making a space in between. Then, the patient's hand is held from the sides at the MCP level and the MCPs are flexed to 90 degrees. Then, two free thumbs from both hands are used to palpate the joint line for every MCP joint. One thumb is pressed firmly for a power causing whitening of the distal thumb nail, while the other thumb is pushed intermittently in and out to assess for swelling (fluctuation of fluid).

MCP 5 swelling either in right and/or left hand positivity

PIP 2 swelling either in
MCP scissor technique:

The examiner should make a scissor-like shape with his/her fingers, joining the index and middle fingers together while joining the ring and little finger together, making a space in between. Then, the patient's hand is held from the sides at the MCP level and the MCPs are flexed to 90 degrees. Then, two free thumbs from both hands are used to palpate the joint line for every MCP joint. One thumb is pressed firmly for a power causing whitening of the distal thumb nail, while the other thumb is pushed intermittently in and out to assess for swelling (fluctuation of fluid). PIP 4-finger:

The examiner's thumb and index finger of one hand should hold each PIP from the side and press firmly until the whitening of distal fingers from low blood supply is clear. With the thumb and index finger of the other hand, the examiner should hold the same PIP-joint from anteroposterior direction and push intermittently in and out to look for swelling (fluctuation of fluid).

PIP 4-finger:

The examiner's thumb and index finger of one hand should hold each PIP from the side and press firmly until the whitening of distal fingers from low blood supply is clear. With the thumb and index finger of the other hand, the examiner should hold the same PIP-joint from anteroposterior direction and push intermittently in and out to look for swelling (fluctuation of fluid).

Wrist 2-thumbs:

The examiner thumb should follow the third metacarpal bone on the dorsal aspect of the hand until reaching a dimple at the capitate level. This thumb should exert a firm, continuous pressure on this point until the whitening of the distal thumb nail is clear, with the examiner's other thumb pushing intermittently in and out just half an inch away from the other thumb on wrist joint line looking for swelling (fluctuation of fluid).

Wrist 2-thumbs:

The examiner thumb should follow the third metacarpal bone on the dorsal aspect of the hand until reaching a dimple at the capitate level. This thumb should exert a firm, continuous pressure on this point until the whitening of the distal thumb nail is clear, with the examiner's other thumb pushing intermittently in and out just half an inch away from the other thumb on wrist joint line looking for tenderness (pain felt by the patient).

Laboratory finding

Laboratory finding

Notes: In adult patients $\geq 18$ years of age who present with small joint pain to PCPs, these variables correlated with the final diagnosis of arthritis. Further research work is needed to determine how to use these variables in clinical practice.

Abbreviations: MCP, metacarpophalangeal; PIP, proximal inter-phalangeal; ACPA, anti-citrullinated protein antibodies; PCPs, primary care physicians.

ating the predictive ability of these referral criteria when used by a PCP. To address this deficiency in information, we assessed a large selection of potential indicators of early inflammatory arthritis, including demographic factors, patient-reported complaints, physical examination results, and blood analysis for patients referred to a rheumatologist by their PCP. While no demographic factors were found to be associated with a positive diagnosis, patient-reported loss of appetite, stiffness, and a family history of uveitis showed a statistically significant relationship. After further analysis, loss of appetite was demonstrated to have high specificity and a good PPV, indicating that it would be a useful indicator when used with other similar variables of a need for a rheumatology referral for a patient with suspected inflammatory arthritis.

Using standardized musculoskeletal examination procedures, the identification of swelling in certain joints was found to be indicative of inflammatory arthritis. Swelling of MCP 
2 and 5, and PIP 2 and 3 showed high specificity with high PPVs, while joint tenderness was not found to be a useful factor. A previous study identified MCP 2 and 3, and PIP 3 with the wrist as being the joints most frequently involved in arthritis. ${ }^{14}$ Furthermore, the authors reported that swelling resulted in superior sensitivity in comparison to tenderness, albeit with poorer specificity. The wrist joint has been also described as one of the most commonly involved joints. ${ }^{14}$ In the present analysis, both swelling and tenderness of the wrist were significantly associated with a diagnosis of inflammatory arthritis, providing the highest sensitivities of all the variables investigated.

Out of the large number of factors investigated using blood analysis, RF and ACPA were identified as having the greatest predictive value. Both of these markers have previously been demonstrated to be indicative of rheumatoid arthritis, and have been linked to disease severity. ${ }^{19}$ ACPA has been demonstrated to be the more accurate of the two markers for identifying rheumatoid arthritis, and has been shown to be present much earlier than RF, even before clinical manifestations have become apparent. ${ }^{20,21}$ Our data demonstrate that routine testing for RF and ACPA should be carried out for patients suspected of having inflammatory arthritis, with a positive result being strongly predictive when used with other variables of a need for referral to a rheumatologist. ANA testing in this cohort of patients did not correlate with the final diagnosis of arthritis.

Future research work will assess in particular the validity of these 9 highly correlated variables (Table 5) when used by the PCP in routine clinical practice. It should be noted that the individual variables in this current study were evaluated separately. The question of how many of these variables should be present in order to consider referring the patient to a rheumatologist is not answered here. Therefore, the presence of a single variable should alert the PCP to the potential for inflammatory arthritis, with the discovery of more than one variable indicating an even greater need for a rapid rheumatology referral. Loss of appetite by itself in a patient with small joint pain may not justify the early referral to a rheumatologist based on improper application of the findings of this study. These variables then need to be tested collectively in a separate study to determine how many of them should be present to justify early referral. It is then that the definitive criteria can be determined.

A recent systematic literature review identified areas of delay to care for patients with inflammatory arthritis and potential solutions for each. ${ }^{22}$ One of these areas was from primary care to rheumatology referral ${ }^{22}$ with several suggested solutions including patient self-administered questionnaires ${ }^{23,24}$ and use of Gait, Arms, Legs and Spine screening examination by physical therapists to detect RA. ${ }^{25}$
Other areas of delay were from rheumatology referral to rheumatology assessment with several solutions including triage of referrals, referral forms, triage clinics, rapid access services, and early arthritis clinics. ${ }^{22}$ In a multicenter retrospective cohort of RA patients, only $41 \%$ of patients with RA were started on therapy within 6 months of presumed onset of disease, and $78 \%$ of the delay was attributable to processes/events that occurred before the patients ever saw a rheumatologist. ${ }^{26}$

Another potential reason for extended referral delays is poor musculoskeletal examination technique in the primary care setting, with improved training during medical school and continuing education programs being advocated. ${ }^{11}$ Furthermore, there is a lack of standardized methodology and defined competencies in MSK examination for use in the diagnosis of inflammatory arthritis. 14,27,28 $^{2}$

We think this study is unique in its design as it was based on a strict methodology among group of patients attending primary care centers in Saudi Arabia. All PCPs received training in performing the specified techniques included in this study. The findings of this study can be utilized to create definitive criteria shortening the delay in referrals. Further efforts should be made by whatever approach determined by local health authorities to assure early rheumatology clinic evaluation. It is hoped that the dream of early referral and management of patients with arthritis could become a reality. ${ }^{29}$

There were some limitations in the study. Firstly, the final diagnoses of the patients were not specified; a larger population may have allowed for comparisons to be made between different inflammatory conditions. Secondly, the study was carried out in a single country, which limits the applicability of the data to a global population. This is particularly important when considering the differences in health care systems. In Saudi Arabia, the specialty of the physician first consulted is dependent on patient choice, while in other countries a PCP referral is necessary for a visit to a specialist. As in the former case, many patients choose to initially visit an orthopedic surgeon, the extension of the referral guidelines produced in the present study to clinics of other specialties may therefore be appropriate. ${ }^{16}$

\section{Conclusion}

It is widely acknowledged that early diagnosis and initiation of treatment for inflammatory arthritis significantly improve patient outcome. It is therefore essential that the time between symptom onset and rheumatologist assessment is minimized. In the present study, we addressed the lack of available criteria for aiding the PCP in identification of the patients who require early referral to a specialist. Using extensive statistical analysis of data from a cohort of patients referred to a 
rheumatology clinic, we have identified 9 variables with high specificity and predictive value for a diagnosis of inflammatory arthritis: loss of appetite, swelling of MCP 2 or MCP 5 , swelling of PIP 2 or PIP 3, wrist swelling, wrist tenderness, RF positivity, and ACPA positivity. Furthermore, the inclusion of standardized physical examination techniques should greatly improve their accuracy when used by the PCP. Future research work should determine precisely validated criteria for early referral in a primary care setting.

\section{Acknowledgments}

The authors gratefully acknowledge Alzaidi Chair of Research in Rheumatic Diseases for supervising and funding this project, Pfizer Inc. for funding the investigations conducted in this study, and AbbVie Inc. for funding the ultrasonography for this project. We would also like to thank Amira Farid, Enas Abdeldaim, and Jomana Ajawi for their help with conducting this study.

\section{Author contributions}

All authors contributed toward data analysis, drafting and revising the paper and agree to be accountable for all aspects of the work.

\section{Disclosure}

The authors report no conflicts of interest in this work.

\section{References}

1. American College of Rheumatology Subcommittee on Rheumatoid Arthritis Guidelines. Guidelines for the management of rheumatoid arthritis: 2002 Update. Arthritis Rheum. 2002;46(2):328-346.

2. Emery P, Breedveld FC, Dougados M, Kalden JR, Schiff MH, Smolen JS. Early referral recommendation for newly diagnosed rheumatoid arthritis: evidence based development of a clinical guide. Ann Rheum Dis. 2002;61(4):290-297.

3. Finckh A, Liang MH, van Herckenrode CM, de Pablo P. Long-term impact of early treatment on radiographic progression in rheumatoid arthritis: a meta-analysis. Arthritis Rheum. 2006;55(6):864-872.

4. Nell VP, Machold KP, Eberl G, Stamm TA, Uffmann M, Smolen JS. Benefit of very early referral and very early therapy with diseasemodifying anti-rheumatic drugs in patients with early rheumatoid arthritis. Rheumatology (Oxford). 2004;43(7):906-914.

5. van Nies JA, Krabben A, Schoones JW, Huizinga TW, Kloppenburg M, van der Helm-van Mil AH. What is the evidence for the presence of a therapeutic window of opportunity in rheumatoid arthritis? A systematic literature review. Ann Rheum Dis. 2014;73(5):861-870.

6. Gamez-Nava JI, Gonzalez-Lopez L, Davis P, Suarez-Almazor ME. Referral and diagnosis of common rheumatic diseases by primary care physicians. Br J Rheumatol. 1998;37(11):1215-1219.

7. van der Linden MP, le Cessie S, Raza K, et al. Long-term impact of delay in assessment of patients with early arthritis. Arthritis Rheum. 2010;62(12):3537-3546

8. Glazier RH, Badley EM, Lineker SC, Wilkins AL, Bell MJ. Getting a grip on arthritis: an educational intervention for the diagnosis and treatment of arthritis in primary care. J Rheumatol. 2005;32(1):137-142.

9. Suresh E. Diagnosis of early rheumatoid arthritis: what the nonspecialist needs to know. $J R$ Soc Med. 2004;97(9):421-424.
10. Tan YK, Østergaard M, Conaghan PG. Imaging tools in rheumatoid arthritis: ultrasound vs magnetic resonance imaging. Rheumatology (Oxford). 2012;51(Suppl 7):vii36-vii42.

11. Akesson K, Dreinhöfer KE, Woolf AD. Improved education in musculoskeletal conditions is necessary for all doctors. Bull World Health Organ. 2003;81(9):677-683.

12. Bell MJ, Badley EM, Glazier RH, Poldre P. A pilot study to determine the effect of patient educators on medical students' and residents' skills in joint examination. Acad Med. 1997;72(10):919.

13. Altschuler EL, Cruz E, Salim SZ, et al. Efficacy of a checklist as part of a physical medicine and rehabilitation clerkship to teach medical students musculoskeletal physical examination skills: a prospective study. Am J Phys Med Rehabil. 2014;93(1):82-89.

14. Almoallim H, Attar S, Jannoudi N, et al. Sensitivity of standardised musculoskeletal examination of the hand and wrist joints in detecting arthritis in comparison to ultrasound findings in patients attending rheumatology clinics. Clin Rheumatol. 2012;31(9):1309-1317.

15. Naing L. Sample size for sensitivity and specificity studies. Available from: http://www.kck.usm.my/ppsg/statistical_resources/samplesize_forsensitivity_specificitystudiesLinNaing.xls. Accessed 23 March 2004.

16. Hussain W, Noorwali A, Janoudi N, et al. From symptoms to diagnosis: an observational study of the journey of rheumatoid arthritis patients in Saudi Arabia. Oman Med J. 2016;31(1):29-34.

17. Fautrel B, Benhamou M, Foltz V, et al. Early referral to the rheumatologist for early arthritis patients: evidence for suboptimal care. Results from the ESPOIR cohort. Rheumatology (Oxford). 2010;49(1): $147-155$.

18. Raza K, Stack R, Kumar K, et al. Delays in assessment of patients with rheumatoid arthritis: variations across Europe. Ann Rheum Dis. 2011;70(10):1822-1825.

19. Katchamart W, Koolvisoot A, Aromdee E, Chiowchanwesawakit P, Muengchan C. Associations of rheumatoid factor and anti-citrullinated peptide antibody with disease progression and treatment outcomes in patients with rheumatoid arthritis. Rheumatol Int. 2015;35(10): 1693-1699.

20. Farid SSh, Azizi G, Mirshafiey A. Anti-citrullinated protein antibodies and their clinical utility in rheumatoid arthritis. Int J Rheum Dis. 2013;16(4):379-386.

21. Nishimura K, Sugiyama D, Kogata Y, et al. Meta-analysis: diagnostic accuracy of anti-cyclic citrullinated peptide antibody and rheumatoid factor for rheumatoid arthritis. Ann Intern Med. 2007;146(11):797-808.

22. Villeneuve E, Nam JL, Bell MJ, et al. A systematic literature review of strategies promoting early referral and reducing delays in the diagnosis and management of inflammatory arthritis. Ann Rheum Dis. 2013;72(1):13-22.

23. Bell MJ, Tavares R, Guillemin F, Bykerk VP, Tugwell P, Wells GA. Development of a self-administered early inflammatory arthritis detection tool. BMC Musculoskelet Disord. 2010;11:50.

24. Callahan LF, Pincus T. A clue from a self-report questionnaire to distinguish rheumatoid arthritis from noninflammatory diffuse musculoskeletal pain. The P-VAS:D-ADL ratio. Arthritis Rheum. 1990;33(9): 1317-1322.

25. Beattie KA, Macintyre NJ, Pierobon J, et al. The sensitivity, specificity and reliability of the GALS (gait, arms, legs and spine) examination when used by physiotherapists and physiotherapy students to detect rheumatoid arthritis. Physiotherapy. 2011;97(3):196-202.

26. Tavares R, Pope JE, Tremblay JL, et al. Time to disease-modifying antirheumatic drug treatment in rheumatoid arthritis and its predictors: a national, multicenter, retrospective cohort. J Rheumatol. 2012;39(11): 2088-2097.

27. Coady DA, Walker DJ, Kay LJ. Teaching medical students musculoskeletal examination skills: identifying barriers to learning and ways of overcoming them. Scand J Rheumatol. 2004;33(1):47-51.

28. Dacre J, Haq I. Assessing competencies in rheumatology. Ann Rheum Dis. 2005;64(1):3-6.

29. Kovacs D, Torralba KD, Fox DA, Solomon DH, Panush RS. Reflecting on early arthritis. J Rheumatol. 2012;39(11):2059-2061. 


\section{Publish your work in this journal}

Open Access Rheumatology: Research and Reviews is an international, peerreviewed, open access journal publishing original research, reports, editorials, reviews and commentaries on all aspects of clinical and experimental rheumatology in the clinic and laboratory including the following topics: Pathology, pathophysiology of rheumatological diseases; Investigation, treatment and management of rheumatological diseases; Clinical trials and novel pharmacological approaches for the treatment of rheumatological disorders. The manuscrip management system is completely online and includes a very quick and fair peer-review system, which is all easy to use. Visit http://www.dovepress.com/ testimonials.php to read real quotes from published authors. 